\title{
Optimal position of lipped acetabular liners to improve stability in total hip arthroplasty-an intraoperative in vivo study
}

\author{
Raphael Hau ${ }^{1,2,3,4}$, Joshua Hammeschlag ${ }^{2}$, Christopher Law ${ }^{1,2}$ and Kemble K. Wang ${ }^{1 *}$ (D)
}

\begin{abstract}
Background: Lipped or elevated acetabular liners are frequently used in total hip arthroplasty to improve stability. However, the optimal position of the lip is not known. The purpose of this study was to determine the optimal position of lipped acetabular liners in total hip arthroplasty performed with a posterior approach.

Methods: In 14 hips, lipped trial liners were placed intraoperatively in various positions around the posterior clock-face of the implanted acetabular shell component. For each liner position, stability of the hip was tested at maximal hip flexion with gradually increasing internal rotation until subluxation occurred, at which point the position of the hip was measured using smartphone accelerometer-based goniometers. Smartphone goniometers were first validated against a computer-assisted navigation system. Post-operative radiographs were analyzed for cup inclination angle, cup anteversion angle, and femoral offset.

Results: Mean cup inclination angle in our series was $31^{\circ} \pm 6^{\circ}$. The most common liner position that imparted the greatest stability to posterior subluxation was posteriorly and inferiorly (4 o'clock position for left hip, or 8 o'clock position for right hip). The range for most stable liner position for different patients varied from postero-superior (11 o'clock/1 o'clock position) to directly inferior (6 o'clock position). Comparing a non-lipped liner to a lipped liner placed in the optimal position, the average difference in internal rotation gained before dislocation was $23^{\circ}$. There was no association between cup inclination or anteversion angle with liner position of greatest stability.

Conclusion: In hip replacements performed through a posterior approach and with mean cup inclination angle of $31^{\circ} \pm 6^{\circ}$, placing the lip of the elevated liner in the postero-inferior quadrant may impart more stability than in the postero-superior quadrant.
\end{abstract}

Keywords: Elevated liner, Instability, Total hip arthroplasty

\section{Introduction}

Instability following total hip arthroplasty remains a significant problem and accounts for up to $34 \%$ of revisions in major joint registries [1-3]. It is the highest cause of revision in the early postoperative period [1]. Many intraoperative factors contribute to stability and need to be carefully addressed, including optimizing tissue tension, acetabular and femoral component positions, and

\footnotetext{
* Correspondence: kemble.wang@gmail.com

${ }^{1}$ Department of Orthopaedic Surgery, Box Hill Hospital, Eastern Health, 8

Arnold Street, Box Hill, Melbourne, VIC 3128, Australia

Full list of author information is available at the end of the article
}

prosthesis head/neck size ratio [4]. One additional method often employed to improve stability is the use of a lipped or elevated acetabular liner.

While non-lipped liners have the same depth around its entire circumference, lipped liners have an increased height in one segment of the rim. This theoretically increases the jump distance required for the prosthetic femoral head before dislocation can occur in the direction of the elevated rim [5]. Since its introduction by Charnley [6], the use of the lipped liner has increased. In a large series by the Mayo Clinic, lipped liners were used in more than $80 \%$ of primary total hip arthroplasties [5].

C The Author(s). 2018 Open Access This article is distributed under the terms of the Creative Commons Attribution 4.0 International License (http://creativecommons.org/licenses/by/4.0/), which permits unrestricted use, distribution, and 
Although not universally accepted, several large studies have shown that the use of a lipped liner is associated with reduced risk of instability or revision for instability [5, 7-9].

Despite its popularity and apparent usefulness, optimal positioning of the elevated portion of the lipped liner has never been formally established. In hips performed with a posterior approach, the majority of dislocations occur in the posterior direction $[5,10]$. It would be logical, therefore, that the elevated part of the liner should be placed in the posterior half of the acetabular shell. However, to the best of our knowledge, there is no evidence in literature to suggest that the postero-superior quadrant is the optimal location as is often traditionally assumed $[4,7,11]$. Clinically and anecdotally, most hip dislocations occur in a position of high hip flexion such as when getting out of a low chair or a low bed. This seems to be supported by biomechanical studies showing that high hip flexion is the primary requirement for posterior dislocation [12-14]. Similarly, the most commonly relied -on maneuver intraoperatively in testing for instability in the posterior approach is with the hip in high flexion and gradually increasing internal rotation until subluxation occurs $[4,11]$. The vector of the force imparted on the acetabular liner during this movement is typically postero-inferior as internal rotation increases.

Therefore, in the present study, we aim to determine what is the optimal position for placing a lipped acetabular liner in reducing instability for uncemented total hip replacements performed through a posterior approach. We hypothesize that the optimal position may not be in the traditionally assumed postero-superior quadrant.

\section{Methods}

This study was granted ethics approval by the institutional ethical review board (approval number P06/14).

\section{Validation of smartphone goniometry}

In order to obtain objective and accurate measurements of hip positions intraoperatively, we used smartphone accelerometer-based goniometers (SPG). Several studies have shown the usefulness and reliability of this technique in measuring in vivo as well as in vitro joint angles [15-17]. We used freely available apps downloaded from the App Store ("Joint Goniometry") on two smartphones (Apple, Cupertino, CA, USA) simultaneously and conducted our own validation by comparing it to an established method of determining joint angles using computer-assisted navigation system ("OrthoNav", Stryker, Kalamazoo, MI, USA). The SPGs were used in the in vivo part of this study because it is less invasive than navigation pins which are required for computer-assisted navigation systems (CAN).

An anatomically accurate sawbone model of the pelvis, left femur, and left tibia was positioned in the lateral decubitus position and stabilized on a table. Navigation pins were inserted into the pelvis and femur as would be in a navigated hip replacement operation. Textiles were wrapped around the sawbones to simulate soft tissue. One smartphone each was attached to the lateral femur and the anterior tibia. The SPGs and CAN were both calibrated in neutral position $\left(0^{\circ}\right.$ of hip adduction, flexion, and internal rotation). Flexion angle was gradually increased in increments of $5^{\circ}$, as determined by CAN measurements, until $90^{\circ}$ was reached. At each of these increments, SPG readings were recorded, and the whole process from extension to flexion was repeated 10 times.

For internal rotation measurements, the hip was initially placed in neutral adduction/abduction, $90^{\circ}$ of flexion and $0^{\circ}$ of internal rotation. The femur was then gradually internally rotated in increments of $5^{\circ}$ (as determined by CAN) while SPG measurements were recorded. The process was repeated 10 times.

For the purpose of the current study, acceptable error range was defined as $3^{\circ}$ on either side of the "gold standard," i.e., CAN measurements.

\section{In vivo liner position testing}

Fourteen hips in 14 patients were included for the purpose of this study. Age of patients was $67 \pm 10$ years (range 45-85). Males and females were equally divided. BMI was $28 \pm 10$. Thirteen patients had a diagnosis of osteoarthritis, and one patient had a primary diagnosis of rheumatoid arthritis.

All patients underwent the same surgical protocol and were operated on by the same surgeon. The operation was performed in the lateral decubitus position using a posterior Kocher-Langenbeck approach. Patients were positioned using a standard pelvic support with two anterior bolsters positioned level at the anterior superior iliac spine (ASIS) and one midline posterior bolster over the sacrum, thereby holding the pelvis vertical on the operating table. Uncemented and hybrid prosthesis (Continuum cup and Avenir / Collarless Polished Taper Stem, Zimmer, Warsaw, IN, USA) were used. Bearing surface for all patients was chrome and cobalt on highly cross-linked polyethylene. Acetabular components were implanted with a target inclination angle of $30-35^{\circ}$, with anteversion to closely match the patient's native anatomy, using the transverse acetabular ligament as guide. Target femoral component anteversion was $10-15^{\circ}$, with a target combined anteversion of $35-45^{\circ}$. The largest prosthetic femoral heads allowed by the implanted cup were used. Short external rotators were repaired with non-absorbable trans-osseous sutures at the completion of component implantation.

Hip stability testing was performed using a trial liner with a $10^{\circ}$ elevated rim. Both the acetabular shell and liner have 12 notches around its circumference that 
allowed adjustment of the liner position by increments of $30^{\circ}$ or one "hour" on the clock-face. The direction in which the middle of the elevated rim was pointing was designated as the direction of the liner. Twelve o'clock is defined as directly superior, or in line with the patient's torso and the long axis of the operating table. The ASIS was used as a guide for the antero-superior quadrant (the 1 o'clock or 11 o'clock position, Fig. 1). For each patient, the liner was trialed in seven positions in the posterior half of the clock-face from 12 o'clock to 6 o'clock. A smartphone was placed on the lateral thigh and another on the anterior tibia, both under sterile plastic covering, and secured to the patient with sterile tape. The hip joint was placed in the neutral position, and the SPGs were calibrated for both flexion and internal rotation.

For each liner position, stability was tested in $90^{\circ}$ of hip flexion and neutral abduction with gradual increase in internal rotation until subluxation occurred. This is a common method for trialing hip stability intraoperatively and has been reported by others $[4,11]$. The maximal amount of internal rotation before subluxation occurred for each liner position was then documented.

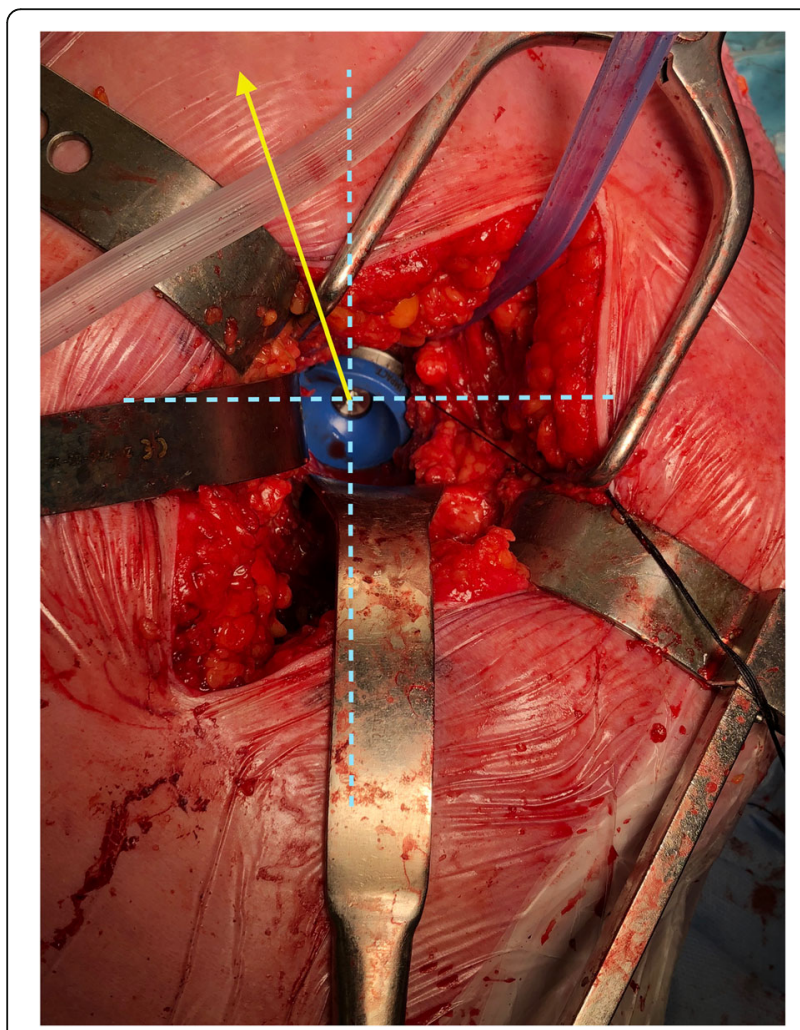

Fig. 1 Intraoperative photo demonstrating the left hip with trial liner. Solid yellow line with arrow points to the ASIS and is designated as the 11 o'clock position. Dotted vertical blue line represents the axis of the patient's body and is the 12 and 6 o'clock reference. The image demonstrates lipped liner being trialed in the posterosuperior quadrant (2 o'clock position)
Postoperative radiographs were obtained for every patient prior to discharge. Cup inclination angle was measured using the method described by Tannast et al. [18], cup anteversion angle was measured using the method described by Murray [19], and femoral offset was measured using the method described by Lechler et al. [20].

Statistical analyses were performed using Matlab (2017, MathWorks, Natick, MA, USA). Unless otherwise stated, averages are expressed as mean \pm standard deviation.

\section{Results}

\section{Smartphone goniometry validation}

Good correlation can be seen between CAN and SPG measurements as shown in Figs. 2 and 3. For all joint angles, the SPG falls within the clinically acceptable range. SPG measurements were remarkably consistent, with the standard error of the mean being less than $0.5^{\circ}$ for all joint angles measured.

\section{In vivo testing}

Median acetabular shell size used was $58 \mathrm{~mm}$ diameter (range 50-62 mm). Six 36-mm and eight 32-mm femoral head components were used.

As seen in Fig. 4, the most common stable position for the lip of the liner was in the postero-inferior quadrant (8 o'clock for right hip, 4 o'clock for left hip). The equal second most common stable positions were 7 o'clock and 9 o'clock (5 o'clock and 3 o'clock for left hip). Converting this to degrees, the average for the most stable position was at $115^{\circ}$ (direct superior $=0^{\circ}$, direct posterior $=90^{\circ}$ ).

The range for most stable liner position for different patients varied from postero-superior (11 o'clock/1 o'clock position) to directly inferior (6 o'clock position).

Of the liner positions measured, the most common lip position that conferred the least stability was at 12 o'clock (Fig. 5). This was followed by the 6 o'clock position.

Comparing a non-lipped liner to a lipped liner placed in the optimal position, the average difference in internal rotation gained prior to occurrence of subluxation was $23^{\circ}(p=0.003)$.

As measured on post-operative radiographs, cup inclination angle was $31^{\circ} \pm 6^{\circ}$ (Fig. 6), and cup anteversion angle was $17^{\circ} \pm 5^{\circ}$. Post-operative femoral offset measured $105 \pm 5 \%$ of the contralateral side.

There was no significant association found between most stable liner position and cup inclination $\left(R^{2}=0.09\right.$, $p>0.05)$ or anteversion angles $\left(R^{2}=0.11, p>0.05\right)$. Three hips had cup inclination angle of $>35^{\circ}\left(36^{\circ}, 38^{\circ}\right.$, and $41^{\circ}$ ). Of these, all three demonstrated most stable liner position in the postero-inferior quadrant. Results were also analyzed with head sizes separated into $36 \mathrm{~mm}$ $(N=6)$ and $32 \mathrm{~mm}(N=8)$ diameters. The most common optimal liner position for 36-mm heads was the $8 / 4$ o'clock position $(N=3,50 \%)$, with the second most 
Hip Flexion

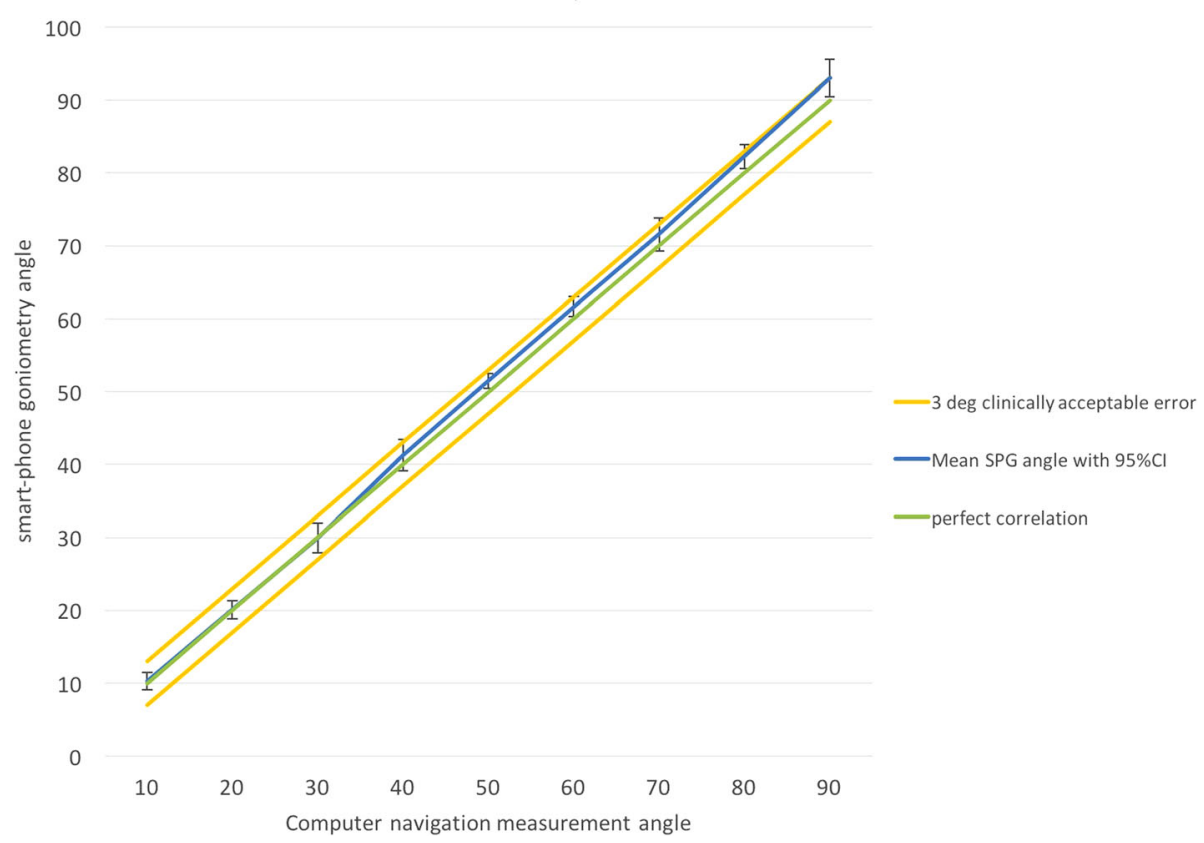

Fig. 2 Correlation of smartphone goniometer reading with computer-assisted navigation for hip flexion. At all joint angles measured, mean smartphone readings were within a $3^{\circ}$ clinically acceptable error range. SPG: smartphone goniometer

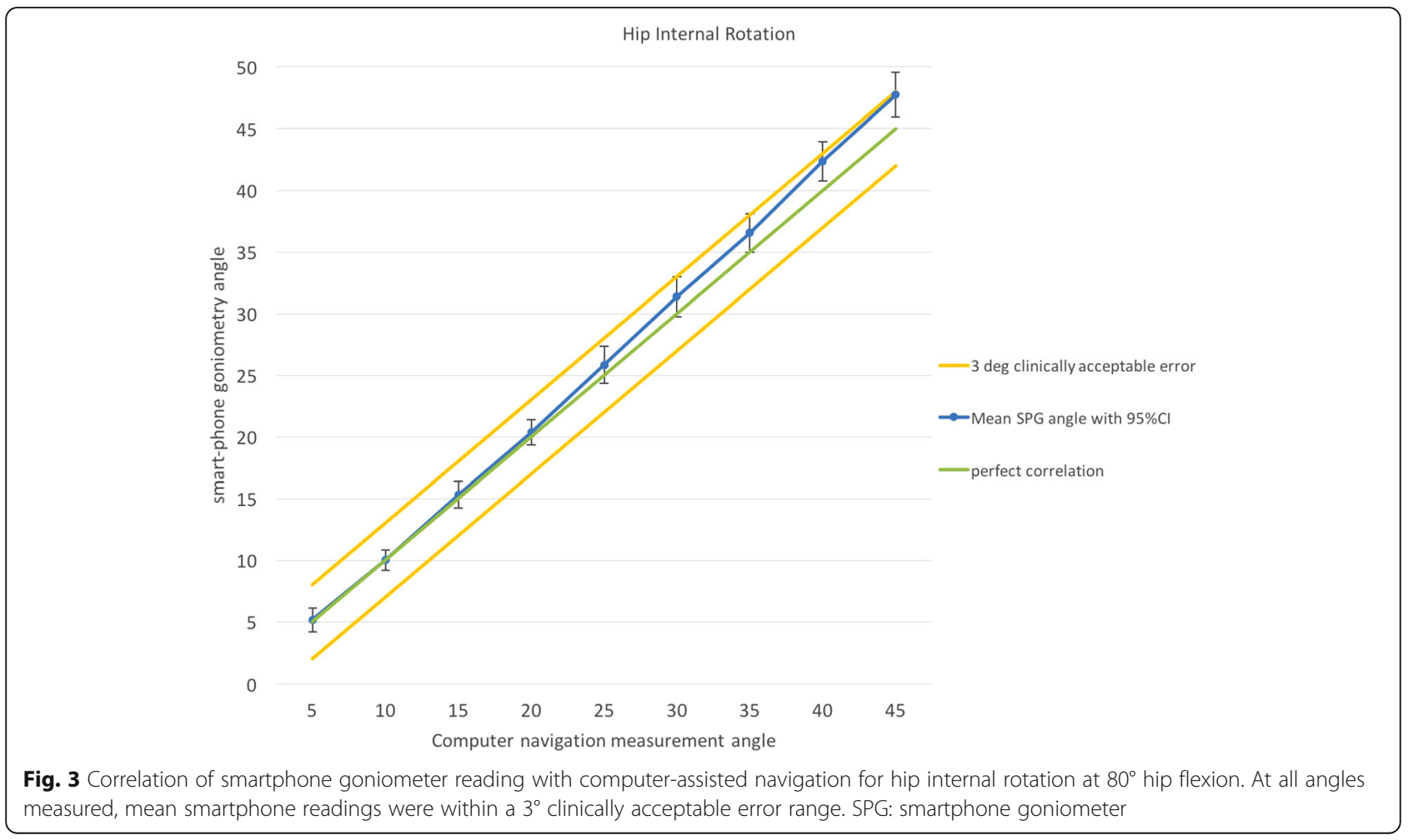




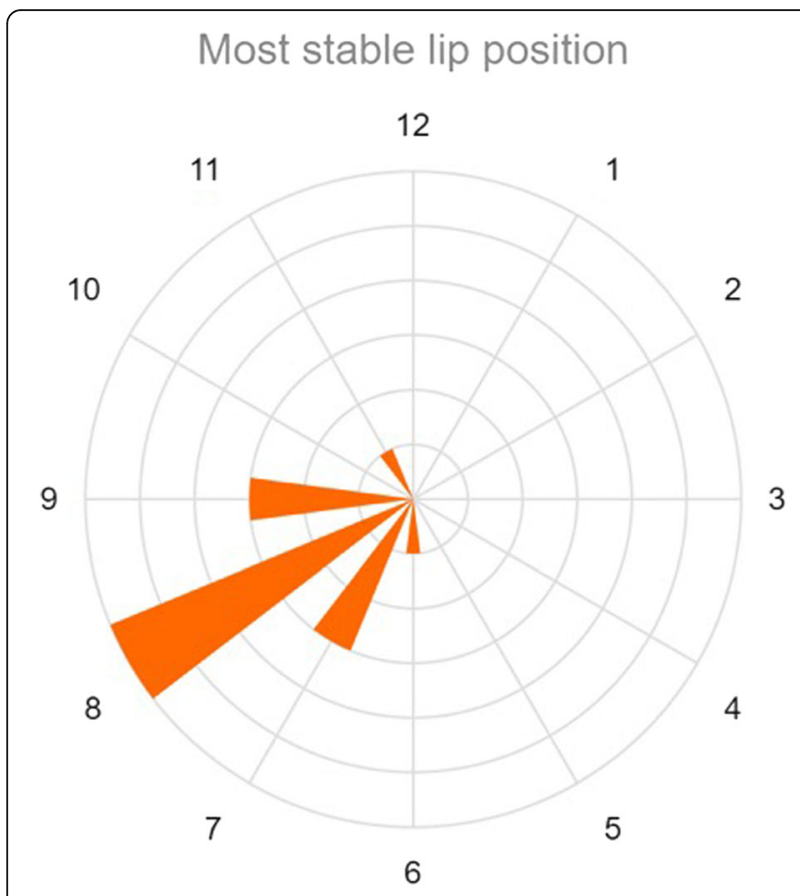

Fig. 4 Most stable lip position for elevated liners (transcribed for right hip). Length of the clock "hands" represent number of patients. The most common position tested that imparted greatest stability in each hip was at the 8 o'clock position, i.e., in the postero-inferior quadrant

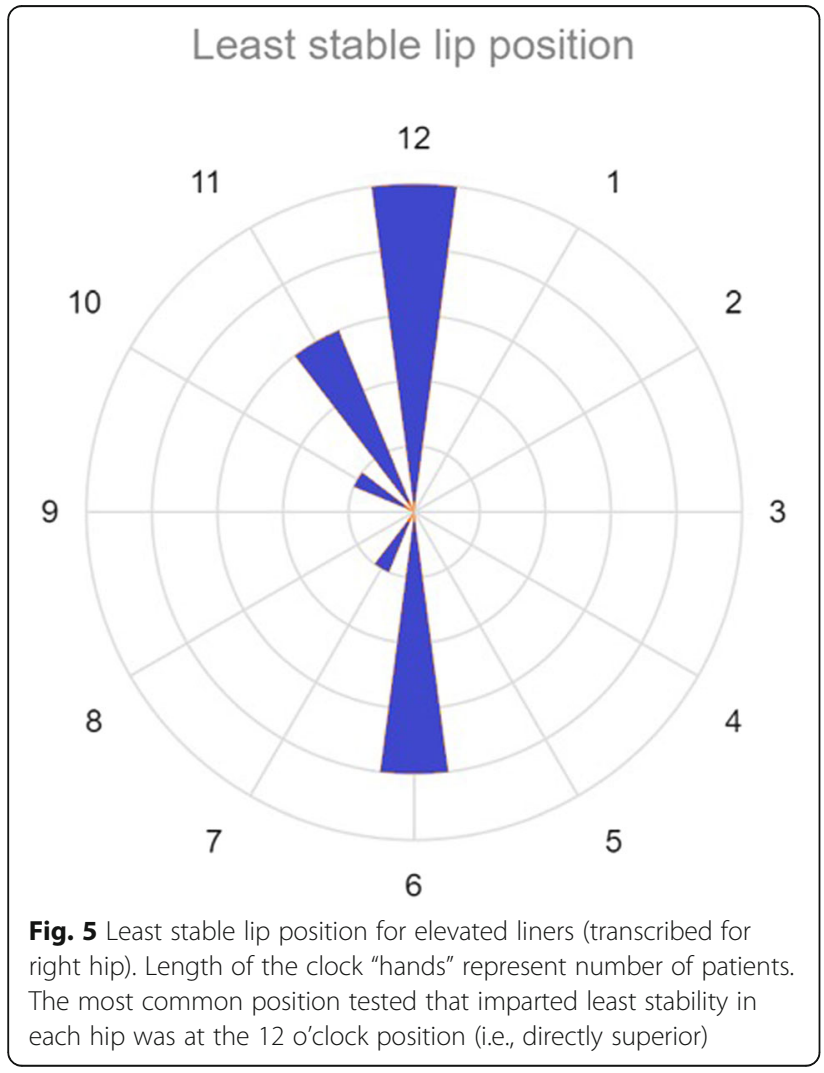

common being the $3 / 9$ o'clock position $(N=2,33 \%)$. The most common optimal liner position for 36-mm heads was also the $8 / 4$ o'clock position $(N=3,38 \%)$, with the second most common being the 5/7 o'clock position $(N=2,25 \%)$.

\section{Discussion}

Lipped or elevated acetabular liners are frequently used in total hip arthroplasty to improve stability. Our results show that lipped liners placed in the postero-inferior quadrant appeared to allow more internal rotation prior to subluxation and hence increased stability, when compared to those placed in the postero-superior quadrant.

It is unclear how the prevailing practice of placing the lip of the liner in the postero-superior quadrant was first established. A search of the literature reveals no supporting evidence. The practice was first introduced by Charnley in 1972 [6], when he modified the scalloped liner into one with a long postero-superior wall. The surgical approach used by Charnley and his peers then was mainly the trans-trochanteric approach, and dislocations were frequently associated with non-union or displacement of the trochanteric osteotomy. In addition, prosthetic femoral head sizes were much smaller at 22 $\mathrm{mm}$ than today's femoral heads, while poorer quality polyethylene meant greater liner wear particularly in the superior portion. We postulate that the mechanics of instability in that setting may be different to those seen in the modern total hip arthroplasty performed through a posterior approach. These factors may have influenced early surgeons in placing lipped liners in the postero-superior quadrant, a practice that has continued to this day.

Sultan et al. [11] tested the effect on stability of using a lipped liner intraoperatively and compared it with a non-lipped liner. All liners were tested in the postero-superior quadrant in the 10 or 2 o'clock position. Their method of testing was similar to the present study, with the hips being placed into high flexion and then gradually internally rotated until subluxation occurred. However, measurements were performed using a traditional goniometer which can give rise to inaccuracies especially in the intraoperative setting. In the present study, liner position was tested in multiple positions and measurements were performed more objectively with the use of a validated smartphone goniometer.

Sultan et al. found that when all else was equal, compared to a neutral liner, using a lipped liner at the 10 or 2 o'clock position resulted in an increase of $8^{\circ}$ in the amount of internal rotation needed to cause posterior dislocation. Our results show that when comparing neutral liner to an optimally placed lipped liner resulted in an increase of $23^{\circ}$ in the amount of internal rotation needed to cause subluxation. One possible explanation for this difference is that an optimally placed lipped liner 


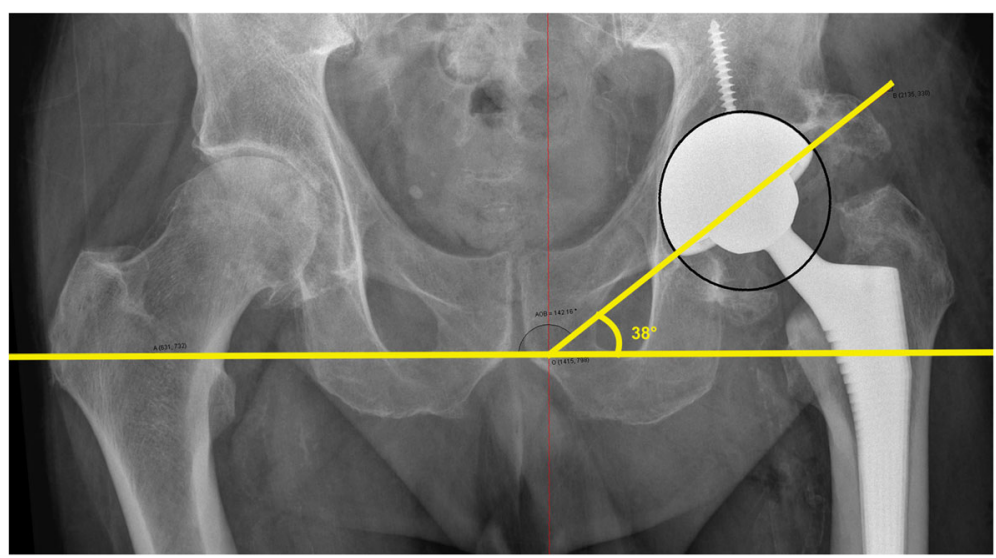

Fig. 6 Post-operative antero-posterior radiograph of the pelvis with measurements of cup inclination. This particular cup measured $38^{\circ}$ inclination

may confer further stability than a lipped liner placed routinely in the postero-superior quadrant.

Use of a lipped liner is not without its controversy. Some authors have raised concerns that it can reduce range of motion and cause impingement, increased polyethylene wear debris, or levering and dislocation in the opposite direction to the elevated lip [21, 22]. However, strong evidence exist that by far most dislocations in hips performed through a posterior approach occur in the posterior direction and any potential disadvantages of a lipped liner is offset by the reduced risk of posterior dislocations associated with its use [5, 7-9].

We believe one strength of this study is that it is an in vivo study. Although many other factors (such as femoral version, acetabular version, head-neck ratio) can contribute to hip instability, by testing multiple liner positions in each individual patient after implantation of the acetabular and femoral components, these potentially confounding factors are inherently controlled for. The use of a validated SPG system also removes much of the inaccuracies of measuring joint angles intraoperatively.

We acknowledge weaknesses to this study. While hip flexion and internal rotation can be measured with relative accuracy using the SPG, liner position in the acetabular shell may not be as accurate. We used the line of the patient's body, axis of the operating table, and the anterior superior iliac spine (ASIS) as a guide to the position of the liner on the clock-face. Ultimately, our study hopes to help other surgeons decide where to place the lipped liner intraoperatively, and in most cases, these visual cues are the only intraoperative guides available in determining what the acetabular orientation is. Secondly, although we measured postoperative cup inclination, anteversion, and femoral offset radiographically, we did not perform routine postoperative computed-tomography or other three-dimensional studies to allow accurate measurement of femoral anteversion and leg length. Thirdly, two different femoral head sizes (32 mm and $36 \mathrm{~mm}$ ) were used, potentially introducing a new confounding variable. Finally, the average cup inclination angle in our series $\left(31^{\circ} \pm 6^{\circ}\right)$ are on the lower side of what is usually aimed for, as recommended by Lewinnek et al. [23]. It is possible that optimal liner position may differ if cup inclination was lower. However, within the range of cup inclination and anteversion angles in our series, we did not detect any correlation with optimal liner position.

\section{Conclusion}

When tested intraoperatively, a lipped liner placed in the postero-inferior quadrant (8 o'clock for right hip or 4 o'clock for left hip) is more likely to confer greater stability against posterior dislocation in total hip replacements performed through a posterior approach. This appears to hold true in our cohort where the average cup inclination is $31^{\circ}$. However, the results may not be generalizable for higher cup inclination angles.

\section{Acknowledgements \\ Not applicable}

Funding

None

Availability of data and materials

The datasets used and/or analyzed during the current study are available from the corresponding author on reasonable request.

\section{Authors' contributions}

KKW analyzed the data and was the primary author of the manuscript, JH co-conceived the study and was a contributor in the manuscript, $\mathrm{CL}$ analyzed the data and was a contributor in the manuscript, and RH conceived the study and was a contributor in the manuscript. All authors read and approved the final manuscript.

\section{Ethics approval and consent to participate}

This study was approved under the Northern Health Institutional Ethics Review Board. Approval number P06/14. Written consent was obtained from all participants to participate in this study

Consent for publication

Not applicable 


\section{Competing interests}

The authors declare that they have no competing interests.

\section{Publisher's Note}

Springer Nature remains neutral with regard to jurisdictional claims in published maps and institutional affiliations.

\section{Author details}

'Department of Orthopaedic Surgery, Box Hill Hospital, Eastern Health, 8 Arnold Street, Box Hill, Melbourne, VIC 3128, Australia. ${ }^{2}$ Department of Orthopaedic Surgery, Northern Health, Melbourne, 185 Cooper St, Epping, Melbourne, VIC 3076, Australia. ${ }^{3}$ Monash University, Melbourne, Wellington Road, Clayton, Melbourne, VIC 3800, Australia. ${ }^{4}$ Epworth Eastern Hospital, Melbourne, 1 Arnold St, Box Hill, Melbourne, VIC 3128, Australia.

Received: 8 July 2018 Accepted: 8 November 2018

Published online: 19 November 2018

\section{References}

1. Australian Orthopaedic Association National Joint Replacement Registry. Annual Report. 2016

2. New Zealand Joint Replacement Registry. 17 Year Report - Jan 1999 to Dec 2015. 2016.

3. Havelin LI, Robertsson O, Fenstad AM, Overgaard S, Garellick G, Furnes O. A Scandinavian experience of register collaboration: the Nordic Arthroplasty Register Association (NARA). J Bone Jt Surgery-American Vol. 2011;93(Suppl 3):13-9. https://doi.org/10.2106/JBJS.K.00951.

4. Sculco PK, Cottino U, Abdel MP, Sierra RJ. Avoiding hip instability and limb length discrepancy after total hip arthroplasty. Orthop Clin North Am. 2016; 47:327-34. https://doi.org/10.1016/j.ocl.2015.09.006.

5. Cobb TK, Morrey BF, Ilstrup DM. The elevated-rim acetabular liner in total hip arthroplasty: relationship to postoperative dislocation. J Bone Joint Surg Am. 1996;78:80-6.

6. Eftekhar NS. Dislocation and instability complicating low friction arthroplasty of the hip joint. Clin Orthop Relat Res. 1976;121:120-5.

7. Rogers M, Blom AW, Barnett A, Karantana A, Bannister GC. Revision for recurrent dislocation of total hip replacement. Hip Int. 2009:19:109-13.

8. Insull PJ, Cobbett H, Frampton CM, Munro JT. The use of a lipped acetabular liner decreases the rate of revision for instability after total hip replacement: a study using data from the New Zealand joint registry. Bone Jt J. 2014:96(B):884-8.

9. Guo L, Yang Y, An B, Yang Y, Shi L, Han X, et al. Risk factors for dislocation after revision total hip arthroplasty: a systematic review and meta-analysis. Int J Surg. 2017;38:123-9. https://doi.org/10.1016/j.ijsu.2016.12.122.

10. Werner BC. Instability after total hip arthroplasty. World J Orthop. 2012;3:122. https://doi.org/10.5312/wjo.v3.i8.122.

11. Sultan PG, Tan V, Lai M, Garino JP. Independent contribution of elevated-rim acetabular liner and femoral head size to the stability of total hip implants. J Arthroplast. 2002;17:289-92. https://doi.org/10.1054/arth.2002.30415.

12. Scifert CF, Brown TD, Lipman JD. Finite element analysis of a novel design approach to resisting total hip dislocation. Clin Biomech. 1999;14:697-703. https://doi.org/10.1016/S0268-0033(99)00054-6.

13. Nadzadi ME, Pedersen DR, Yack HJ, Callaghan JJ, Brown TD. Kinematics, kinetics, and finite element analysis of commonplace maneuvers at risk for total hip dislocation. J Biomech. 2003;36:577-91. https://doi.org/10.1016/ S0021-9290(02)00232-4

14. Bunn A, Colwell CW, D'Lima DD. Effect of head diameter on passive and active dynamic hip dislocation. J Orthop Res. 2014;32:1525-31. https://doi. org/10.1002/jor.22659.

15. Dietz MJ, Sprando D, Hanselman AE, Regier MD, Frye BM. Smartphone assessment of knee flexion compared to radiographic standards. Knee. 2017; 24:224-30. https://doi.org/10.1016/j.knee.2016.11.014.

16. Graham D, Suzuki A, Reitz C, Saxena A, Kuo J, Tetsworth K. Measurement of rotational deformity: using a smartphone application is more accurate than conventional methods. ANZ J Surg. 2013;83:937-41. https://doi.org/ 10.1111/ans.12371.

17. Franko Ol, Bray C, Newton PO. Validation of a scoliometer smartphone app to assess scoliosis. J Pediatr Orthop. 2012;32:e72-5. https://doi.org/10.1097/ BPO.0b013e31826bb109.

18. Tannast M, Zheng G, Anderegg C, Burckhardt K, Langlotz F, Ganz R, et al. Tilt and rotation correction of acetabular version on pelvic radiographs. Clin
Orthop Relat Res. 2005;NA;182-90. doi:https://doi.org/10.1097/01.blo. 0000167669.26068.c5.

19. Murray DW. The definition and measurement of acetabular orientation. J Bone Joint Surg Br. 1993;75:228-32.

20. Lechler P, Frink M, Gulati A, Murray D, Renkawitz T, Bücking B, et al. The influence of hip rotation on femoral offset in plain radiographs. Acta Orthop. 2014;85:389-95. https://doi.org/10.3109/17453674.2014.931196.

21. Girard J, Kern G, Migaud H, Delaunay C, Ramdane N, Hamadouche M. Primary total hip arthroplasty revision due to dislocation: prospective French multicenter study. Orthop Traumatol Surg Res. 2013;99:549-53.

22. Marchetti E, Krantz N, Berton C, Bocquet D, Fouilleron N, Migaud H, et al. Component impingement in total hip arthroplasty: frequency and risk factors. A continuous retrieval analysis series of 416 cup. Orthop Traumatol Surg Res. 2011;97:127-33. https://doi.org/10.1016/j.otsr.2010.12.004.

23. Lewinnek GE, Lewis JL, Tarr R, C. LC, Zimmerman J. Dislocations after total hip replacement arthroplasties. J Bone Jt Surg Am. 1978:217-20.
Ready to submit your research? Choose BMC and benefit from:

- fast, convenient online submission

- thorough peer review by experienced researchers in your field

- rapid publication on acceptance

- support for research data, including large and complex data types

- gold Open Access which fosters wider collaboration and increased citations

- maximum visibility for your research: over $100 \mathrm{M}$ website views per year

At $\mathrm{BMC}$, research is always in progress.

Learn more biomedcentral.com/submissions 